Pak. j. sci. ind. res. Ser. A: phys. sci. 201457 (1) 1-9

\title{
Modification of Ntezi Bentonite Structure by Hydrochloric Acid: Process Kinetics and Structural Properties of the Modified Samples
}

\author{
Regina Obiageli Ajemba \\ Department of Chemical Engineering, Nnamdi Azikiwe University, PMB 5025, Awka, Anambra, Nigeria
}

(received September 17, 2012; revised November 29, 2012; accepted December 5, 2012)

\begin{abstract}
Bentonite from Ntezi was modified by reacting it with different concentrations of hydrochloric acid solutions. The modified samples were analysed by x-ray fluorescence. The kinetics of the modification reaction was studied by performing the experiment at different temperatures and times. Results of the analysis of the modified samples showed that the octahedral cations were removed which altered the chemical composition of the bentonite. The surface area and adsorptive capacity of the bentonite were improved after the modification. The kinetic studies showed that the acid modification reaction is controlled by the product layer diffusion and can be represented by $\left[1-(1-X)^{1 / 3}\right]^{2}=\mathrm{k} t$; where, $\mathrm{X}$ is the fraction of the bentonite dissolved at time t. The activation energy was determined to be $24.98 \mathrm{~kJ} / \mathrm{mol}$.
\end{abstract}

Keywords: adsorption, bleaching, activation, kinetic model, chemical treatment, bentonite

\section{Introduction}

Natural clays are acquiring prominence as low-cost adsorbent over the past few decades due to their local and abundant availability and capability to undergo modification. The use of these natural clays is hampered by the presence of net negative charge on the surface and small surface area and these factors have led to the need for research and development in the field of modification of clay surfaces to enhance their adsorptive properties.

Clay minerals vary in their chemical composition and this leads to varying mineralogical properties that include: layer charge, cation exchange capacity, adsorption capacity and morphology (Steudel et al., 2009). Due to the large chemical composition variability, clay minerals are used in different industrial applications such as ceramics, food, chemical and paper industries. Sometimes, the clay minerals are used in their natural state and at other times after some specific modification (Komadel, 2003). One of such modification methods is acid treatment. Acid activation of clay mineral has been studied for years by many researchers (Steudel et al., 2009; Vicente-Rodriguez et al., 1994a; Suarez et al., 1992; Cetisli and Gedikbey, 1990; Bonilla et al., 1981; Rodriguez-Reinoso et al., 1981; Abdul-Latif and Weaver, 1969). Different types of acid treatment have been described in the literature, varying from each other by the nature of the acid used, temperature, and intensity

E-mail: ginaajemba@rocketmail.com and time of the attack. Acid treatment of clay minerals, namely fibrous clays (Myriam et al., 1998; SuarezBarrios et al., 1995; Vincente Rodriguez et al., 1995, 1994a), smectites (Suarez et al., 2001; Prieto et al., 1999; Vincente Rodriguez et al., 1994b) and Kaolinite (Belver et al., 2002) is widely applied in order to optimise their physicochemical behaviour, aiming better industrial properties. Xianzhen and Chuyi (1990) have done acid treatments with sepiolite, concluding that the silica obtained could be competitive in different industrial ways, with that obtained by precipitation. The acid treatment of clay minerals is usually referred to as acid activation, because it increases the specific surface area and the number of active sites of the solids. This treatment modifies the surfaces of clays by disaggregations of particles, possible elimination of mineral impurities and removal of metal-exchange cations. The common commercial use of acid-treated clay minerals is bleaching or decolourations of oils (Christidis et al., 1997; Srasra et al., 1989; Taylor et al., 1989; Kheok and Lim, 1982) and in general in the fields of adsorption and catalysis (Mokaya and Jones, 1995; Fahn and Fenderl, 1983).

Two types of octahedral sheets occur in clay minerals: dioctahedral, where two-thirds of the octahedral sites are occupied by trivalent cations, such as $\mathrm{Al}^{3+}$ or $\mathrm{Fe}^{3+}$; and the trioctahedral type, mostly occupied by divalent cations, such as $\mathrm{Mg}^{2+}$; the negative charge of the layers is balanced by hydrated exchangeable cations in the 
interlayers, mostly $\mathrm{Ca}^{2+}, \mathrm{Mg}^{2+}$, and $\mathrm{Na}^{+}$(Tomic et al., 2011; Tyagi et al., 2006). Acid modified natural bentonite are the subject of many researchers (Amari et al., 2010; Madejova et al., 2009; Steudel et al., 2009; Venaruzzo et al., 2002; Bergaya and Lagaly, 2001). The first step in modifying the clay mineral structure with acid is a separation of exchangeable cations from protons. The second step is flushing $\mathrm{Al}, \mathrm{Mg}$, and $\mathrm{Fe}$ from octahedral and tetrahedral sheets, in a way that $\mathrm{SiO}_{4}$ groups of tetrahedral sheets remain mostly intact.

In this work, hydrochloric acid modification of bentonite from Ntezi was carried out to increase the surface area and adsorption capacity and also to investigate the structural changes that occurred in the modified samples. Special emphasis was paid to the kinetics of the modification process to study its mechanism.

\section{Materials and Methods}

Bentonite samples were mined from the site, dried and grinded to $0.212 \mathrm{~mm}$ particle size. These samples were reacted with different concentrations $(2,4,6,8,10$, and $12 \mathrm{~mol} / \mathrm{L}$ ) of hydrochloric acid solution. Ten grams of the sized fraction was reacted with already determined volume of the acid solution in a $250 \mathrm{~mL}$ bottomed flask and heated to a fixed temperature of $70{ }^{\circ} \mathrm{C}$, while, on a magnetic stirring plate stirring was continued throughout the reaction duration. After completion of the reaction time, the suspension was immediately filtered to separate undissolved materials, washed three times with distilled water. The resulting solutions were analysed for aluminum, magnesium and iron ions using MS atomic absorption spectrophotometer (AAS 4000 Perkin Elmer). The residue was washed to neutrality with distilled water, air dried and oven dried at $80^{\circ} \mathrm{C}$ and labeled as NZ0, NZ2, NZ4, NZ6, NZ8, NZ10, and NZ12, where, the numbers denote the acid concentration used in the activation process. To study the kinetics of the dissolution process of the octahedral ions-aluminum, magnesium and iron, the activation was repeated at different times $\left(1\right.$ to $6 \mathrm{~h}$ ) and at different temperatures $\left(70\right.$ to $120^{\circ} \mathrm{C}$ ).

The chemical compositions and intensity change of absorption bands of the solid residues were determined by x-ray fluorescence (XRF, Philips PW 2400) and fourier transforms infrared (FTIR, Shimadzu S8400) spectroscopy, respectively. The surface area of the natural and treated samples were determined using the method of ethylene glycol monoethyl-ether (EGME) as developed by Carter et al. $(1986 ; 1965)$, while, the cation exchange capacity (CEC) was determined using the method of Inglethorpe et al. (1993) which involves centrifuging a mixture of few grams of clay with solution of buffered barium chloride for hours and discarding the supernatant, adding distilled water and solution of magnesium sulphate, then titrating the mixture with EDTA.

The bleaching capacity of the natural and acid activated clay samples was investigated by using them to bleach palm oil. About $5 \mathrm{~g}$ of each sample was reacted with refined palm oil and heated to $80^{\circ} \mathrm{C}$ for $30 \mathrm{~min}$. At the completion of the reaction time, the oil was filtered and the bleaching efficiency was determined by measuring the colour of the bleached oils using a uv-vis spectrophotometer (Shimadzu UV mini 1240) at wavelength of $450 \mathrm{~nm}$.

\section{Results and Discussion}

Chemical composition of bentonite samples. The chemical composition of the natural and treated bentonite samples are shown in Table 1. The content of $\mathrm{SiO}_{2}$ was observed to increase as the acid concentration increased up to $10 \mathrm{~mol} / \mathrm{L}$ and decreased with further increase in acid concentration. This could be due to the formation of mullite which protects the clay layers from further acid attack. The contents of the octahedral cations $\left(\mathrm{Al}_{2} \mathrm{O}_{3}, \mathrm{Fe}_{2} \mathrm{O}_{3}\right.$ and $\left.\mathrm{MgO}\right)$ decreased intensely as the acid concentration increased and they were increased with further attack after $10 \mathrm{~mol} / \mathrm{L}$ concentration (Table 1). The behaviour shown by the $\mathrm{Al}_{2} \mathrm{O}_{3}, \mathrm{Fe}_{2} \mathrm{O}_{3}$, and $\mathrm{MgO}$ contents with progressive acid treatment is related to the progressive dissolution of the clay mineral. The octahedral sheet destruction passes the cations into the solution, while, the silica generated by the tetrahedral sheet remains in the solid phase due to its insolubility (Dias et al., 2003). Pesquera et al. (1992) suggest that this free silica generated by the initial destruction of the tetrahedral sheet, is polymerised by the effect of such high acid concentration and is deposited on the undestroyed silicate fractions, thereby protecting it from further acid attack (Vicente-Rodriguez et al., 1994a; Srasra et al., 1989).

Surface area of the activated bentonite. The acid activation was carried out with hydrochloric acid concentration range from $2 \mathrm{~mol} / \mathrm{L}$ to $12 \mathrm{~mol} / \mathrm{L}$. Pushpaletha et al. (2005) reported that the surface area of acid activated bentonite generally increases with increase in acid concentration until a maximum surface area is reached after which it gradually decreases. In this study, the surface area was observed to increase with increase 
Table 1. Chemical composition and $\mathrm{Si} /(\mathrm{Al}+\mathrm{Fe}+\mathrm{Mg})$ of natural and $\mathrm{HCl}$ modified bentonite from Ntezi

\begin{tabular}{|c|c|c|c|c|c|c|c|}
\hline \multirow[t]{2}{*}{ Chemical composition } & \multicolumn{7}{|c|}{ Clay samples } \\
\hline & NZ0 & NZ2 & NZ4 & NZ6 & NZ8 & NZ10 & NZ12 \\
\hline $\mathrm{Al}_{2} \mathrm{O}_{3}$ & 16.54 & 13.87 & 10.23 & 7.09 & 5.94 & 2.41 & 2.88 \\
\hline $\mathrm{SiO}_{2}$ & 54.72 & 59.93 & 65.84 & 69.75 & 72.53 & 75.61 & 75.09 \\
\hline $\mathrm{Fe}_{2} \mathrm{O}_{3}$ & 13.23 & 10.14 & 8.06 & 5.04 & 3.78 & 2.17 & 2.23 \\
\hline $\mathrm{CaO}$ & 0.41 & 0.35 & 0.21 & 0.12 & 0.04 & 0.01 & 0.01 \\
\hline $\mathrm{MgO}$ & 7.10 & 5.36 & 3.19 & 2.16 & 1.49 & 0.52 & 0.54 \\
\hline $\mathrm{K}_{2} \mathrm{O}$ & 0.35 & 0.16 & 0.09 & 0.03 & 0.01 & 0.01 & 0.01 \\
\hline $\mathrm{TiO}_{2}$ & 1.24 & 0.93 & 0.68 & 0.48 & 0.27 & 0.14 & 0.06 \\
\hline $\mathrm{Na}_{2} \mathrm{O}$ & 0.04 & 0.02 & 0.01 & 0.01 & 0.01 & 0.001 & 0.001 \\
\hline $\mathrm{ZnO}$ & 0.89 & 0.57 & 0.38 & 0.19 & 0.11 & 0.04 & 0.02 \\
\hline LOI & 5.28 & 3.85 & 3.16 & 2.42 & 1.94 & 1.65 & 1.11 \\
\hline Total & 99.80 & 95.18 & 91.85 & 87.29 & 86.12 & 82.561 & 81.951 \\
\hline $\mathrm{Si} /(\mathrm{Al}+\mathrm{Fe}+\mathrm{Mg})$ & 1.48 & 2.04 & 3.07 & 4.88 & 6.47 & 14.83 & 13.29 \\
\hline Bleaching efficiency (\%) & 38.9 & 54.97 & 62.87 & 69.82 & 77.45 & 91.64 & 84.06 \\
\hline Surface area $\left(\mathrm{m}^{2} / \mathrm{g}\right)$ & 97 & 136 & 169 & 197 & 245 & 297 & 275 \\
\hline
\end{tabular}

in acid concentration from $2 \mathrm{~mol} / \mathrm{L}$ to $10 \mathrm{~mol} / \mathrm{L}$. A maximum surface area was obtained with $10 \mathrm{~mol} / \mathrm{L}$ $\mathrm{HCl}$ as shown in Fig. 1. This increase in surface area with rise in acid concentration is attributed to the removal of impurities, replacement of exchangeable cations such as $\mathrm{K}^{+}, \mathrm{Na}^{+}$and $\mathrm{Ca}^{2+}$, with hydrogen ions and leaching out of $\mathrm{Al}^{3+}, \mathrm{Fe}^{3+}$ and $\mathrm{Mg}^{2+}$ from the octahedral and tetrahedral sheets which expose the edges of the platelets (Tsai et al., 2007). The decrease in the surface area with further increase in acid concentration could be attributed to the deeper penetration of the acid into the voids and excessive leaching of $\mathrm{Al}^{3+}$, $\mathrm{Fe}^{3+}$ and $\mathrm{Mg}^{2+}$, resulting in the collapse of the crystalline structure (Pesquera et al., 1992).

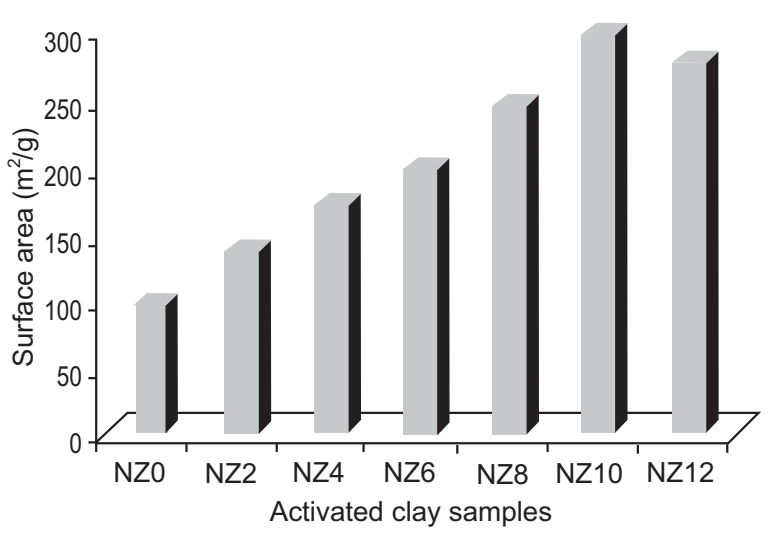

Fig. 1. Surface area of bentonite modified with different acid concentrations.
Cation exchange capacity of the activated samples. The results of the cation exchange capacity of the activated samples showed that the exchange ability of the activated samples decreased as the concentration of the acid used in the activation increased (Fig. 2). With the increase of concentration of hydrochloric acid, the bentonite showed a gradual decrease of the CEC until dissolving with $10 \mathrm{~mol} / \mathrm{L}$ acid. In treatment with $12 \mathrm{~mol} / \mathrm{L} \mathrm{HCl}$ acid, as the $\mathrm{SiO}_{2}$ content decreased, an increase of CEC was observed in comparison with the CEC observed with the sample treated with $10 \mathrm{~mol} / \mathrm{L}$. This is due to the removal of the exchangeable ions from the lattice of the clay samples by the acid hydrogen ion which occupies the vacant sites.

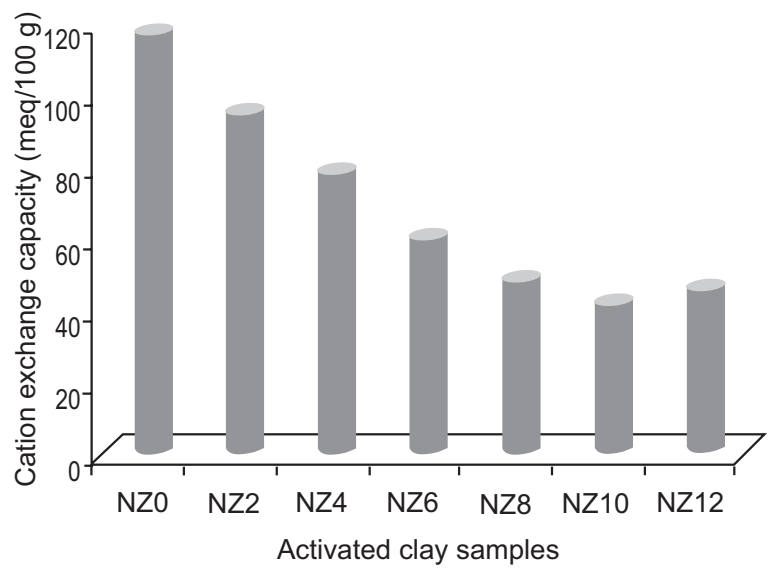

Fig. 2. Cation exchange capacity of the clay samples modified with different acid concentrations. 
Effect of time on the modification of bentonites. Results of the activation process at different times showed that there is a linear relationship between the fraction of the octahedral ions removed and time. This is shown in Figs. 3-5 for the removal of $\mathrm{Al}^{3+}, \mathrm{Fe}^{3+}$ and $\mathrm{Mg}^{2+}$ ions, respectively. Comparison of the rate of removal of these three cations, showed that the removal is in the following order, $\mathrm{Mg}^{2+}>\mathrm{Fe}^{3+}>\mathrm{Al}^{3+}$ as shown in Figs. 3-5.

Effect of temperature on the modification of bentonite. The effect of temperature on the bentonite

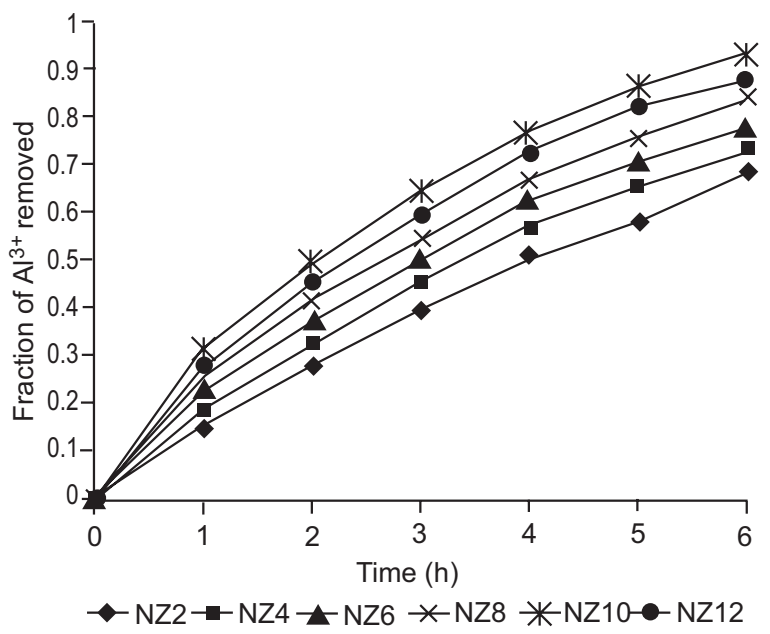

Fig. 3. Plot of fraction of $\mathrm{Al}^{3+}$ removed $v s$ time for samples activated at different acid concentrations.

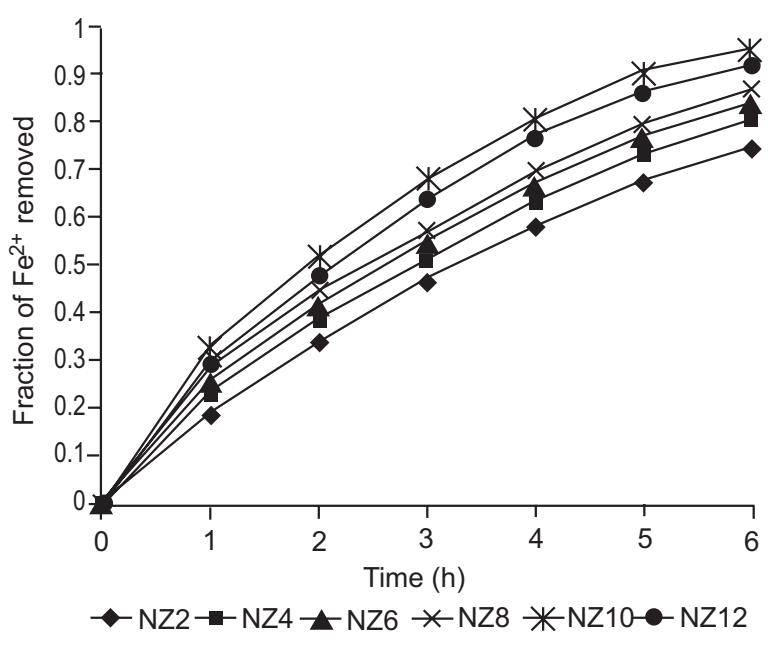

Fig. 4. Plot of fraction of $\mathrm{Fe}^{3+}$ removed $v s$ time for samples activated at different acid concentrations. modification was studied in the range of $70-120{ }^{\circ} \mathrm{C}$. The experimental results are presented in Fig. 6. Data in the figure shows that the dissolution rate of the cations in the acid medium increased as the leaching temperature increases up to the maximum temperature used in this study. The increase in removal rate of the cations could be as a result of high kinetic energy in the system which speeds up the rate of reaction on the surface of the clay. The same trend was reported by others (Numluk and Chaisena, 2012; Xu et al., 2012; Philips and Wills, 1982).

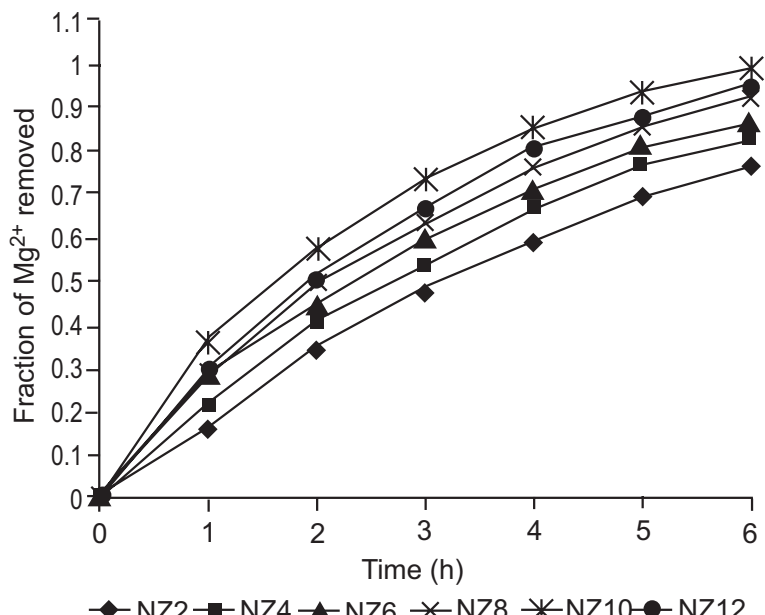

Fig. 5. Plot of fraction of $\mathrm{Mg}^{2+}$ removed $v s$ time for samples activated at different acid concentrations.

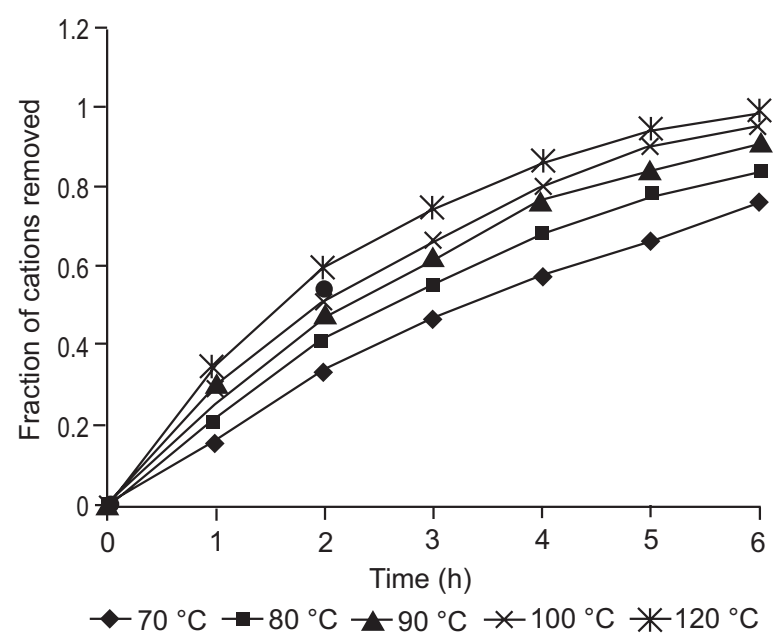

Fig. 6. Plot of fraction of cations removed after modification at different temperatures (using $10 \mathrm{~mol} / \mathrm{L} \mathrm{HCl}$ activated sample). 
Fourier transforms infrared (FTIR) spectroscopy analysis. The FTIR spectra of the natural and hydrochloric acid-leached samples were carried out in the range from $400-4000 \mathrm{~cm}^{-1}$ to study the effect of acidleaching on the clay mineral. The FTIR spectra of the raw and acid-leached samples are shown in Fig. 7-8, respectively. The changes in the functional groups provide the indication of the modifications that occurred during the activation process. During the acid-leaching of the clay samples the protons from the acid medium penetrate into the clay structures attacking the $\mathrm{OH}$ groups thereby causing the alteration in the adsorption bands attributed to the $\mathrm{OH}$ vibrations and octahedral cations. The intensities of the stretching bands observed at $3623,3432,1641$, and $920 \mathrm{~cm}^{-1}$ (associated with $\mathrm{O}-\mathrm{H}$, along with Al-OH stretch) decreased after acidactivation. The increase in the severity of acid caused the disappearance of the stretching bands at 4660, 3694, 2376, and $998 \mathrm{~cm}^{-1}$ assigned to the $\mathrm{H}-\mathrm{O}-\mathrm{H}$ stretching. The peak assigned to Si-O-Si stretch at 788 and 1066 $\mathrm{cm}^{-1}$ remained after acid leaching, similar result was reported by others (Christidis et al., 1997; Komadel et al., 1990). The bands at 525, 690, and $998 \mathrm{~cm}^{-1}$ disappeared after the acid treatment of the clay sample. The transformation of the tetrahedral occurred at 788 $\mathrm{cm}^{-1}$ which was increased after the acid treatment.

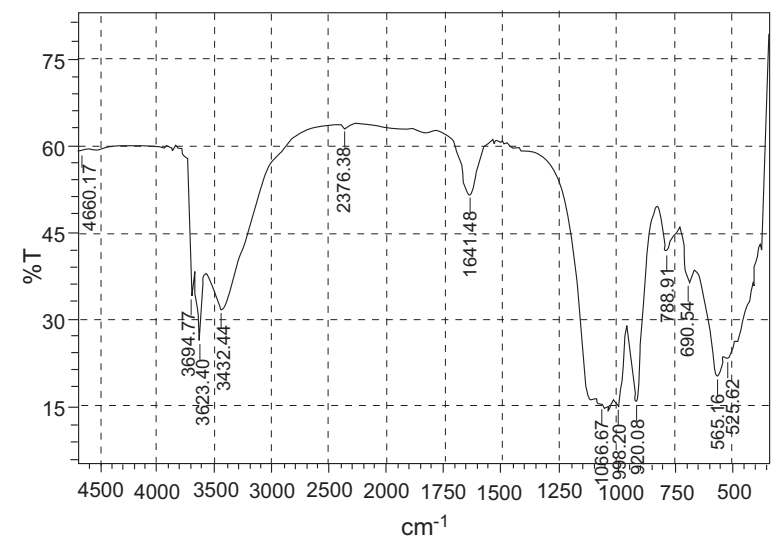

Fig. 7. FTIR spectra of natural Ntezi clay.

Activation kinetics studies. The kinetic studies showed that the acid modification reaction is controlled by the product layer diffusion and can be represented by

$$
\left[1-(1-\mathrm{X})^{1 / 3}\right]^{2}=\mathrm{k} \mathrm{t}
$$

where:

$\mathrm{X}=$ fraction of the bentonite dissolved at time $\mathrm{t}$. The activation energy was determined to be $24.98 \mathrm{~kJ} / \mathrm{mol}$.

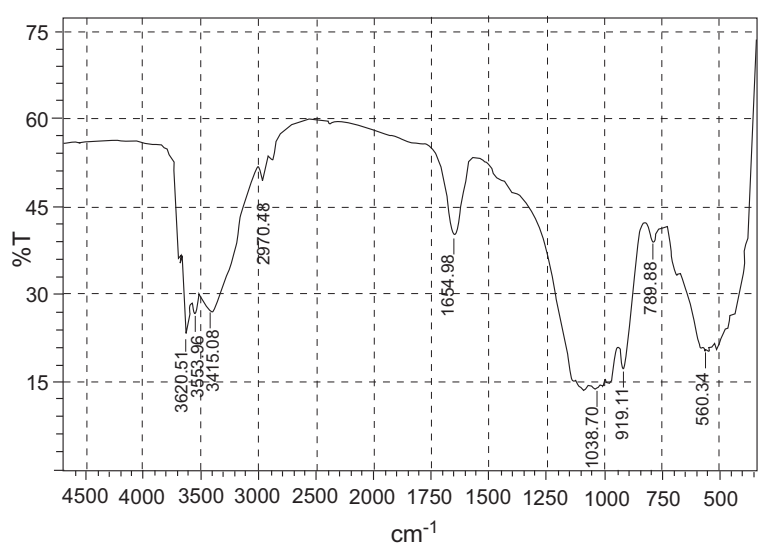

Fig. 8. FTIR spectra of $10 \mathrm{~mol} / \mathrm{L} \mathrm{HCl}$ acid-activated Ntezi clay.

The reaction between a solid and a fluid may be represented by

$$
\text { A (fluid) }+ \text { b B (solid) } \rightarrow \text { products }
$$

The rate of reaction between a solid and a fluid can be expressed by heterogeneous and homogeneous reaction models. According to the shrinking-core model, the reaction is considered to take place at the outer surface of the unreacted particle. When no ash forms, the reacting particle shrinks during reaction and finally disappears. For a reaction of this kind, the following three steps are considered to occur in succession during reaction (Levenspiel, 1972).

1. Diffusion of fluid reactant through the fluid layer to the surface of the solid.

2. Reaction of the fluid reactant and solid on the surface of the solid.

3. Diffusion of the products through the film layer to the bulk fluid.

The slowest of these sequenced steps is the ratedetermining step. If the reaction is controlled by film diffusion, it becomes

$$
X=\left[3 b k_{c} C_{A} / \tilde{n}_{B} R\right] t=k_{f} t
$$

if it is controlled by chemical reaction, it becomes

$$
1-(1-X)^{1 / 3}=\left[b k_{s} C_{A} / \tilde{n}_{B} R\right] t=k_{r} t
$$

the product layer diffusion control is given by

$$
\begin{aligned}
& 1+2(1-X)-3(1-X)^{2 / 3}=\left[2 M_{B} D C_{A} / \tilde{n}_{B} b R^{2}\right] \\
& t=k_{d} t
\end{aligned}
$$


where:

$\mathrm{X}=$ fraction of $\mathrm{B}$ dissolved in $\mathrm{A}, \tilde{\mathrm{n}}_{\mathrm{B}}$ is the molar density of solid reactant $\left(\mathrm{mol} / \mathrm{m}^{3}\right), \mathrm{R}$ is the radius of a sphere $(\mathrm{m}), \mathrm{b}$ is the stoichiometric coefficient of the solid, $\mathrm{k}_{\mathrm{c}}$, $\mathrm{k}_{\mathrm{f}}, \mathrm{k}_{\mathrm{s}}, \mathrm{k}_{\mathrm{r}}$, and $\mathrm{k}_{\mathrm{d}}$ are rate constants, $\mathrm{D}$ is the effective diffusion coefficient $\left(\mathrm{m}^{2} / \mathrm{s}\right), \mathrm{M}_{\mathrm{B}}$ is the molecular weight of $\mathrm{B}$, and $\mathrm{C}_{\mathrm{A}}$ is the concentration of $\mathrm{A}$ in the bulk solution $\left(\mathrm{mol} / \mathrm{m}^{3}\right)$.

The experimental data of Figs. 3-5 were tested with the above kinetic models, but it was determined statistically that the dissolution reaction did not fit the models. The data were then analysed using the kinetic model as developed by Jander (1927) given by:

$$
\left[1-(1-X)^{1 / 3}\right]^{2}=\mathrm{k}_{\mathrm{q}} \mathrm{t}
$$

Using this equation, the plot of $\left[1-(1-\mathrm{X})^{1 / 3}\right]^{2}$ versus time gave straight lines passing through the origin as shown in Figs. 9-11 for $\mathrm{Al}^{3+}, \mathrm{Fe}^{3+}$ and $\mathrm{Mg}^{2+}$, respectively. The coefficient of determination $\left(\mathrm{R}^{2}\right)$ values was used to determine the fitness of the data to the equation. As can be observed from the values of $\mathrm{R}^{2}$, it is evident that the fitness is close to unity for all the data.

The experimental data of Fig. 6 was tested with the kinetic equation and straight lines passing through the origin were obtained as shown in Fig. 12. The apparent reaction rate constants calculated from the slopes of Fig. 12, were plotted against the reciprocal of the temperature according to the Arrhenius equation to

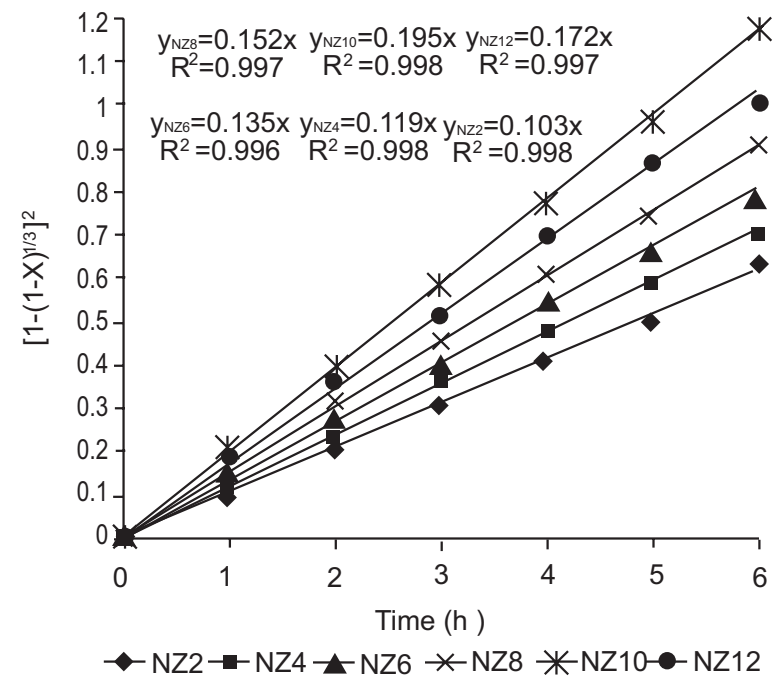

Fig. 9. Plot of $\left[1-(1-\mathrm{X})^{1 / 3}\right]^{2}$ vs time for $\mathrm{Al}^{3+}$ removal at different acid concentrations.

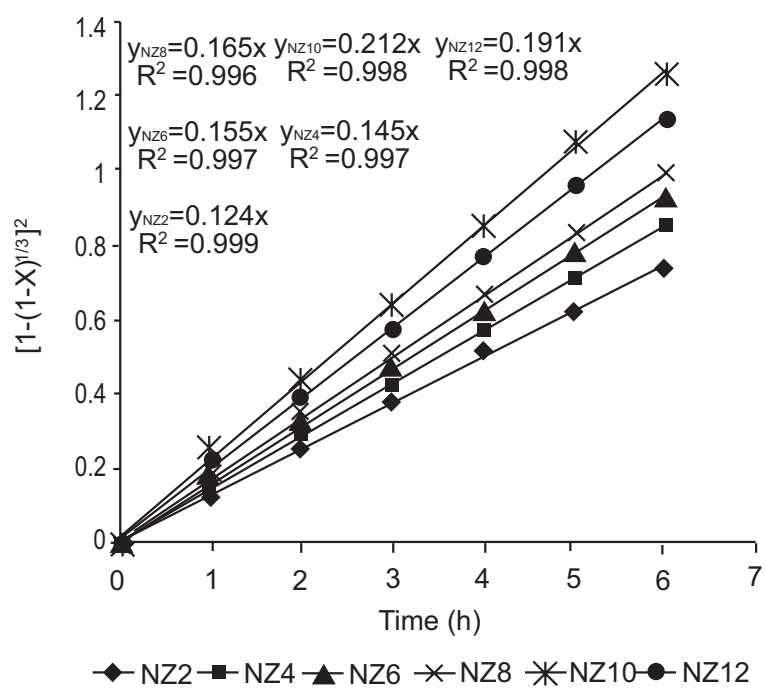

Fig. 10. Plot of $\left[1-(1-\mathrm{X})^{1 / 3}\right]^{2}$ vs time for $\mathrm{Fe}^{3+}$ removal at different acid concentrations.

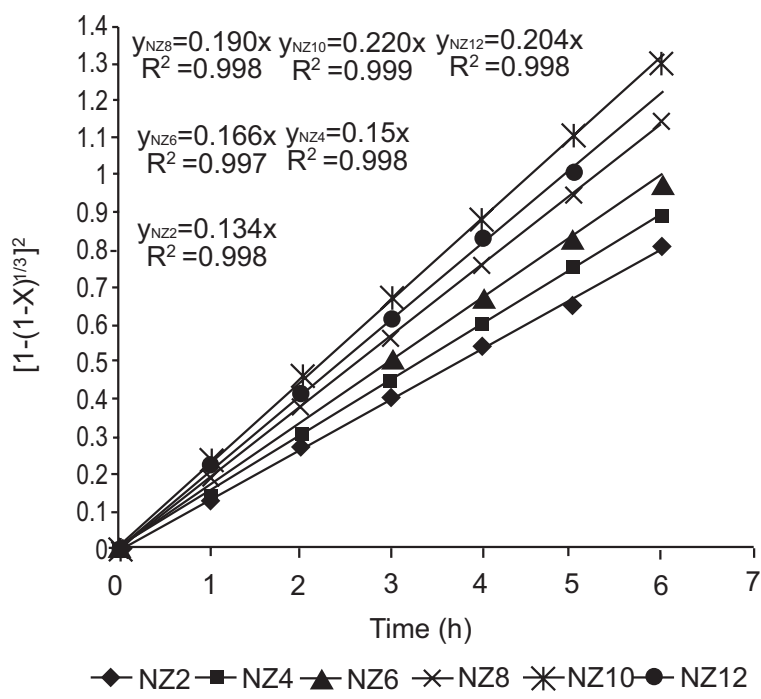

Fig. 11. Plot of $\left[1-(1-\mathrm{X})^{1 / 3}\right]^{2}$ vs time for $\mathrm{Mg}^{2+}$ removal at different acid concentrations.

determine the activation energy of the processes. The activation energy was determined to be $24.98 \mathrm{~kJ} / \mathrm{mol}$ with a correlation coefficient of 0.963 , which is in close agreement with the value calculated by Uzun and Gulfen (2007) of $21.42 \mathrm{~kJ} / \mathrm{mol}$ for the dissolution of red mud in sulphuric acid solution.

Adsorption performance of the activated bentonite. Oils and fats are bleached in order to remove undesired colourants because these colourants can negatively affect the taste of the oil and in part because the colour 


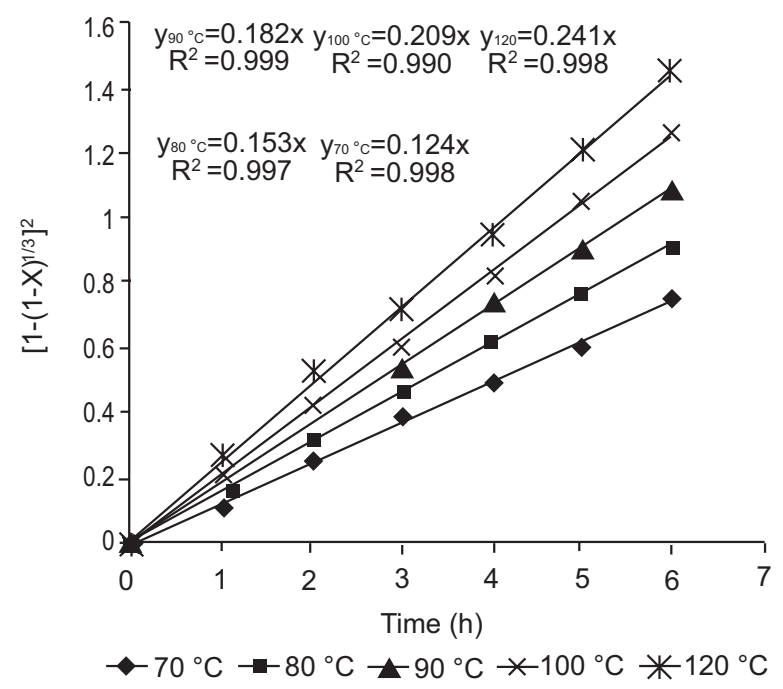

Fig. 12. Plot of $\left[1-(1-\mathrm{X})^{1 / 3}\right]^{2} v s$ time at different temperatures.

would disturb the consumers, therefore, on the whole, these colourants limit use and marketability. In addition to that, some particles or pigments that promote deterioration to oil quality is also being removed during bleaching process mainly due to their pro-oxidative properties that promotes oxidation. As a result, these undesirable pigments are removed using appropriate adsorbents, such as activated clays. To investigate the adsorptive performance of the acid treated samples, the samples were used to adsorb colour pigments from palm oil and the results are presented in Fig. 13. The figure shows that the adsorption power increased gradually as the intensity of the acid treatment increased and reached a maximum with $10 \mathrm{~mol} / \mathrm{L}$ treated sample.

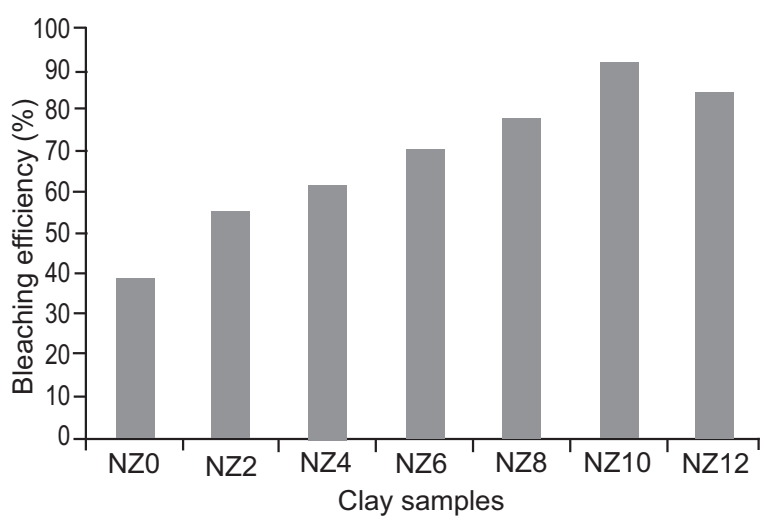

Fig. 13. Plot of the bleaching efficiency of the natural and acid activated Ntezi bentonite.
Further increase in the intensity of treatment caused a reduction in the adsorption capacity and this could be as a result of reduced surface area (Fig. 1) and $\mathrm{Si} /[\mathrm{Al}$ $+\mathrm{Fe}+\mathrm{Mg}$ ] ratio (Table 1 ).

\section{Conclusion}

The structural modifications of Ntezi bentonite after hydrochloric acid activation and kinetics of the process have been investigated in this work. The acid activation caused reorganisation of the clay structures by the removal of the di- and trioctahedral cations and subsequent modifications of the tetrahedral arrangement. These resulted to samples with increased surface area, adsorption capacity, and reduced cation exchange capacity. The activation process could be described by the product layer diffusion kinetic model with activation energy of $24.98 \mathrm{~kJ} / \mathrm{mol}$. The results reveal that acid activation of bentonite with $10 \mathrm{~mol} / \mathrm{l} \mathrm{HCl}$ acid can be employed as an economical technique for modification of bentonite to enhance its surface properties and adsorption capacity.

\section{References}

Abdul-Latif, N., Weaver, C. 1969. Kinetics of acid dissolution of palygorskite (attapulgite) and sepiolite. Clays and Clay Minerals, 17: 169-178.

Amari, A., Chlendi, M., Gannouni, A., Bellagi, A. 2010. Optimised activation of bentonite for toluene adsorption. Applied Clay Sciences, 47: 457-461.

Belver, C., Munoz, M.A.B., Vicente, M.A. 2002. Chemical activation of a kaolin under acid and alkaline conditions. Chemical Materials, 14: 2033 2043.

Bergaya, F., Lagaly, G. 2001. Surface modification of clay minerals. Applied Clay Science, 19: 1-3.

Bonilla, J.L., Lopez-Gonzalez, J.D., Ramirez-Saenz, A., Rodriguez-Reinoso, F., Valenzuela-Calahorro, C. 1981. Activation of a sepiolite with dilute solutions of $\mathrm{HNO}_{3}$ and subsequent heat treatments II: Determination of surface acid centers. Clay Minerals, 16: 173-179.

Carter, D.L., Mortland, M.M., Kemper, W.D. 1986. Specific Surface. In: Methods of Soil Analysis, Part 1, pp. 456-478, $2^{\text {nd }}$ edition, American Society of Agronomy, USA.

Carter, D.L., Heilman, M.D., Gonzalez, C.L. 1965. Ethylene glycol mono-ethyl ether for determining surface area of silicate minerals. Soil Science, 100: 356-360. 
Cetisli, H., Gedikbey, T. 1990. Dissolution kinetics of sepiolite from Eskisehir (Turkey) in hydrochloric and nitric acids. Clay Minerals, 25: 207-215.

Christidis, G.E., Scott, P.W., Dumham, A.C. 1997. Acid activation and bleaching capacity of bentonites from the islands of Milos and Chios, Aegean and Greece. Applied Clay Science, 12: 329-347.

Dias, M.I., Suarez, M.B., Prates, S., Martin-Pozas, J.M. 2003. Characterization and acid activation of Portuguese special clays. Clay Minerals, 38: 537549.

Fahn, R., Fenderl, K. 1983. Reaction products of organic dye molecules with acid-treated montmorillonite. Clay Minerals, 18: 447-458.

Inglethorpe, S.D.J., Morgan, D.J., Highley, D.E., Bloodworth, A.J. 1993. Industrial Mineral Laboratory Manual-Bentonite. British Geological Survey Technical Report, WG/93/20, 116 pp., Mineralogy and Petrology Series, Mineralogy and Petrology Group, British Geological Survey, Nottingham, UK.

Jander, W. 1927. Reactivity of solid minerals. Zernan Anorganice Allgeudter Chemica, 163: 1-12.

Kheok, S.C., Lim, E.E. 1982. Mechanism of palm oil bleaching by montmorillonite clay activated at various acid concentrations. Journal of the American Oil Chemists Society, 59: 129-131.

Komadel, P. 2003. Chemically modified smectites. Clay Minerals, 38: 127-138.

Komadel, P., Schmidt, D., Medejova, J., Cicel, J. 1990. Alteration of smectites by treatment with hydrochloric acid and sodium carbonate solutions. Applied Clay Sciences, 5: 113-122.

Levenspiel, O. 1972. Chemical Reaction Engineering, 357 pp., $2^{\text {nd }}$ edition, John Wiley and Sons, New York, USA.

Madejova, J., Pentrak, M., Palkova, H., Komadel, P. 2009. Near infrared spectroscopy: a powerful tool in studies of acid-treated clay minerals. Vibrations Spectroscopy, 49: 211-218.

Mokaya, R., Jones, W. 1995. Pillared clays and pillared acid-activated clays: A comparative study of physical, acidic and catalytic properties. Journal of Porous Materials, 6: 335-344.

Myriam, M., Suarez, M., Martin-Pozas, J.M. 1998. Structural and textural modifications of palygorskite and sepiolite under acid treatment. Clays and Clay Minerals, 46: 225-231.

Numluk, P., Chaisena, A. 2012. Sulphuric acid and ammonium sulphate leaching of alumina from
Lampang clay. E-Journal of Chemistry, 9: 13641372.

Pesquera, C., Gonzalez, F., Benito, I., Blanco, C., Mendioroz, S., Pajares, J. 1992. Passivation of a montmorillonite by the silica created in acid activation. Journal of Material Chemistry, 2: 907-911.

Phillips, C.V., Wills, K.J. 1982. A laboratory study of the extraction of alumina of smelter grade from China clay micaceous residues by a nitric acid route. Hydrometallurgy, 9: 15-28.

Prieto, O., Vicente, M.A., Banares-Munoz, M.A. 1999. Study of the porous solids obtained by acid treatment of a high surface area saponite. Journal of Porous Materials, 6: 335-344.

Pushpaletha, P., Rugmini, S., Lalithambika, M. 2005. Correlation between surface properties and catalytic activity of clay catalysts. Applied Clay Science, 30: 141-153.

Rodriguez Reinoso, F., Ramirez-Saenz, A., LopezGonzalez, J.D.E.D., Valenzuela-Calahorro, C., Zurita-Herrera, L. 1981. Activation of a sepiolite with dilute solutions of $\mathrm{HNO}_{3}$ and subsequent heat treatments III: Development of porosity. Clay Minerals, 16: 315-323.

Srasra, E., Bergaya, F., Vandammne, H., Arigub, N.K. 1989. Surface properties of an activated bentonite: Decolourization of rapeseed oils. Applied Clay Science, 4: 411-421.

Steudel, A., Batenburg, L.F., Fischer, H.R., Weidler, P.G., Emmerich, K. 2009. Alteration of swelling clay minerals by acid activation. Applied Clay Science, 44: 105-115.

Suarez, M., de Santiago, C., Garcia-Romero, E., Martin-Pozas, J.M. 2001. Textural and structural modifications of saponite from Cerro Del Aguila by acid treatment. Clay Minerals, 36: 483-488.

Suarez, M., Flores, L.V., Martin-Pozas, J.M. 1992. Textural study of palygorskite by acid treatment. Abstracts of Mediterranean Clay Meeting, M.C.M. 92; Lipari (Italy), pp. 132-133.

Suarez-Barrios, M., Flores-Gonzalez, L.V., VicenteRodriguez, M.A., Martin-Pozas, J.M. 1995. Acid activation of palygorskite with $\mathrm{HCl}$ : Development of physicochemical textural and surface properties. Applied Clay Science, 10: 247-258.

Taylor, D.R., Jenkins, D.B., Ungermann, C.B. 1989. Bleaching with alternative layered minerals: a comparison with acid activated montmorillonite for bleaching soy bean oil. Journal of the American Oil Chemists Society, 66: 334-341. 
Tomic, P.Z., Antic Mladenovic, S.B., Babic, B.M., Poharc Logar, V.A., Dordevic, A.R., Cupac, S.B. 2011. Modification of smectite structure by sulphuric acid and characteristics of the modified smectite. Journal of Agricultural Science, 56: 25-35.

Tsai, W.T., Hsu, H.S., Su, T.Y., Lin, K.Y., Lin, C.M., Dai, T.H. 2007. The adsorption of cationic dye from aqueous solution onto acid-activated andersite. Journal of Hazardous Materials, 147: 10561062.

Tyagi, B., Chudasama, C.D., Jasra, R.V. 2006. Determination of structural modification in acid activated montmorillonite clay by FTIR spectroscopy. Spectrochimica Acta Part A, 64: 273-278.

Uzun, D., Gulfen, M. 2007. Dissolution kinetics of iron and aluminium from red mud in sulphuric acid solution. Indian Journal of Chemical Technology, 14: 263-268.

Venaruzzo, J.L., Volzone, C., Rueda, M.L., Ortiga, J. 2002. Modified bentonite clay minerals as adsorbents of $\mathrm{CO}, \mathrm{CO}_{2}$ and $\mathrm{SO}_{2}$ gases. Microporous and Mesoporous Materials, 56: 73-80.

Vicente-Rodriguez, M.A., Lopez-Gonzalez, J.D.,
Banares-Munoz, M.A., Casado-Linarejos, J. 1995. Acid activation of Spanish sepiolite II. Kinetic considerations, development of porosity and acid centers and silica fibers size. Clay Minerals, 30: 315-323.

Vicente-Rodriguez, M.A., Lopez-Gonzalez, J.D., Banares-Munoz, M.A. 1994a. Acid activation of a Spanish sepiolite: Physicochemical characterization, free silica content and surface area of the solids obtained. Clay Minerals, 29: 361-367.

Vicente-Rodriguez, M.A., Suarez-Barrios, M., LopezGonzalez, J.D., Banares-Munoz, M.A. 1994b. Acid activation of a ferrous saponite (griffithite): Physicochemical characterization and surface area of the products obtained. Clays and Clay Minerals, 42: 724-730.

Xianzhen, Y., Chuyi, Z. 1990. Purification of sepiolite and preparation of silica. In: Proceedings of $9^{\text {th }}$ International Clay Conference Strasbourg, pp. 2532.

Xu, Y.M., He, D.M., Shi, J.W., Guan, J., Zhang, Q.M. 2012. Preparation of alumina from retorting residue of oil shale. Oil Shale, 29: 36-50. 